\title{
Effects of increased supratentorial pressure in cats
}

\author{
J. W. F. BEKS
}

From the Department of Neurosurgery, University Hospital, Groningen, Netherlands

SYNOPSIS In 20 cats a cold lesion of the cerebral cortex was produced to bring about a rise of intracranial pressure in order to establish the degree of difference in pressure between various compartments in the skull necessary to produce displacement of cerebral tissue. At certain pressures there was a shift of brain tissue in all animals. When the ventricular pressure increased further, in all animals the arterial pressure increased and in 15 cats we observed a periodic respiration at a mean value of $113 \cdot 1 \pm 4 \cdot 1 \mathrm{mmHg}$. All animals finally had a rapid respiration similar to central neurogenic hyperventilation.

In 1881 two German scientists (Naunyn and Schreiber) reported that as a result of increasing intracranial pressure changes of vegetative functions may occur. In 1902 these changes were described in detail by Harvey Cushing, pioneer of neurosurgery. He recorded increasing arterial pressure, slowing of the pulse, and alteration in the pattern of breathing. Further investigation showed that these reactions could not have been induced by a space-occupying lesion which had led only to increased intracranial pressure, but that these vegetative changes occurred as the result of compression of various structures, caused by displacement of cerebral tissue.

The question arises whether the term 'increased intracranial pressure' is always correct. The expression has indeed significance only if the pressure in various compartments inside the skull is increased to the same degree, which will indeed be the case as long as there is a liquid communication between the various compartments. This is not so once this communication is interrupted, as may happen under pathological conditions-for instance, with herniation of cerebral tissue in the tentorial hiatus.

The mechanism of the displacement of cerebral tissue and the herniation of the brain-stem and its resulting consequences have been described extensively by Pia (1957), Langfitt et al. (1964), and Seeger (1968). Herniation of cerebral tissue in a caudal direction through the tentorial hiatus is considered to be a frequent result of a supratentorially situated space-occupying lesion. If, however, in a closed system, subdivided into different communicating compartments, the pressure always remains equal in those different compartments, displacement of the contents from one compartment to another cannot take place.

\section{METHODS}

In animal experiments we tried to establish the degree of difference in pressure between various compartments necessary to produce displacement of cerebral tissue. In 20 anaesthetized cats a needle was introduced into the right lateral ventricle by stereotactic means and also one into the cisterna magna in order to measure simultaneously the pressure in these two parts of the system. The mean initial pressure was $8.9 \pm 1.5 \mathrm{mmHg}$ infra- as well as supratentorially (Table 1). To bring about a rise of intracranial pressure a cold-induced lesion was made in the cerebral cortex, as described formerly in detail (Beks et al., 1965).

Consequent to this lesion we observed a gradual increase in intraventricular pressure, as well as a rise of pressure in the cisterna magna. At first the increase of pressure in both instances was identical, indicating an open liquid communication between supra- and infratentorial spaces via the tentorial hiatus and the Sylvian aqueduct. Later, however, a discrepancy appeared between the increase of pressure in the two compartments and the pulsations in the infratentorial compartment disappeared. At the moment when we saw the appearance of the discrepancy in the rise of pressure in the supra- and infratentorial spaces, we injected $x$-ray contrast medium by a needle into the right lateral ventricle. 


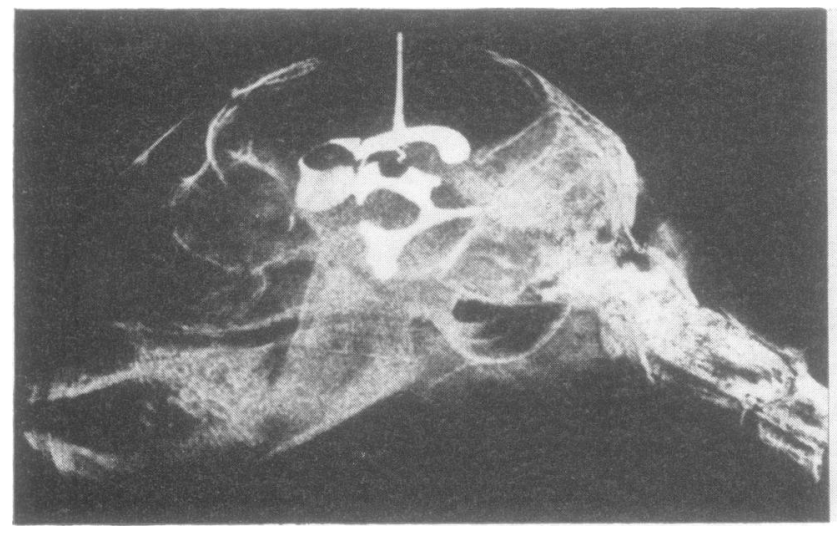

FIG. 1. The Sylvian aqueduct is obstructed at the level of the tentorium.

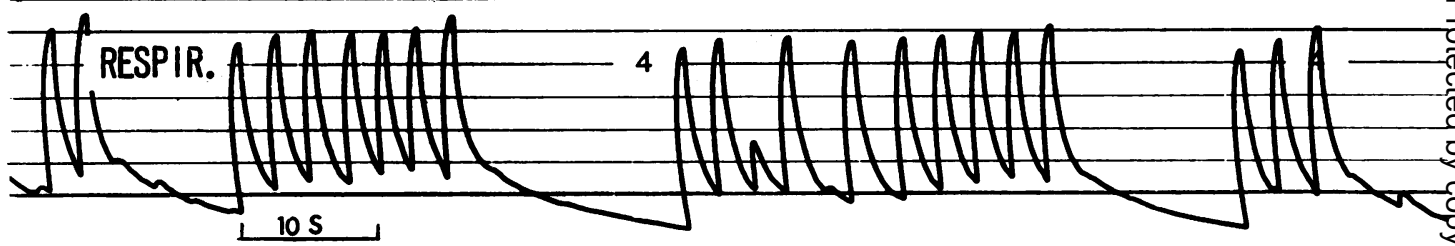

FIG. 2. The periodic respiration seen in 15 cats when the ventricular pressure was $113 \cdot 1 \pm 4 \cdot 1 \mathrm{mmHg}$.

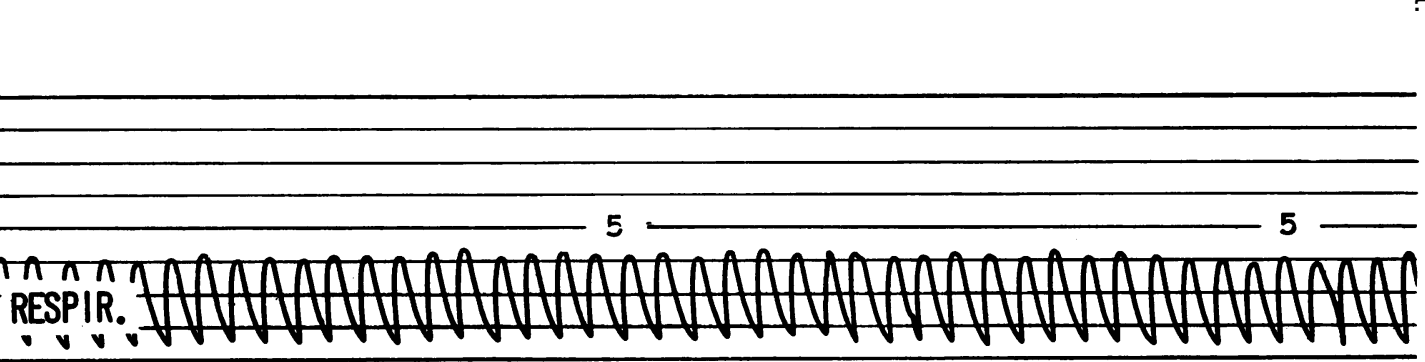

$$
10 \mathrm{~S}
$$

FIG. 3. The rapid respiration similar to central neurogenic hyperventilation which was observed in all test animals.

Films showed that the Sylvian aqueduct was obstructed at the level of the tentorium (Fig. 1). Nor would contrast medium injected into the subdural supratentorial space reach the infratentorial space via the tentorial hiatus. We therefore assumed that the liquid communication between the two compartments had been interrupted. After this we saw the pressure rise considerably in the supratentorial space, while the pressure in the infratentorial space remained static at first and finally rose a little. This late rise of pressure can perhaps be ascribed to an increase of volume in the infratentorial space by further herniation of cerebral tissue via the tentorial hiatus.

The mean pressure in the ventricular system at the moment the pulsation in the great cistern disappeared 
TABLE 1

SUMMARY OF CHANGES OF PRESSURE IN INTRACRANIAL COMPARTMENTS AFTER COLD LESION

\begin{tabular}{|c|c|c|c|}
\hline \multirow[t]{2}{*}{$\begin{array}{l}\text { Case } \\
\text { no. }\end{array}$} & \multirow{2}{*}{$\begin{array}{c}\text { Initial } \\
\text { intraventricular } \\
\text { pressure } \\
(\mathrm{mmHg})\end{array}$} & \multicolumn{2}{|c|}{$\begin{array}{c}\text { Cisternal pressure } \\
(\mathrm{mmHg})\end{array}$} \\
\hline & & Initial & Highest \\
\hline 1 & 6 & 7 & 37 \\
\hline 2 & 10 & 10 & 35 \\
\hline 3 & 10 & 10 & 38 \\
\hline 4 & 9 & 8 & 32 \\
\hline 5 & 7 & 7 & 29 \\
\hline 6 & 10 & 10 & 37 \\
\hline 7 & 10 & 10 & 40 \\
\hline 8 & 8 & 7 & 37 \\
\hline 9 & 10 & 10 & 36 \\
\hline 10 & 11 & 11 & 35 \\
\hline 11 & 7 & 7 & 35 \\
\hline 12 & 11 & 11 & 35 \\
\hline 13 & 7 & 7 & 32 \\
\hline 14 & 10 & 10 & 35 \\
\hline 15 & 7 & 7 & 36 \\
\hline 16 & 10 & 10 & 35 \\
\hline 17 & 8 & 8 & 35 \\
\hline 18 & 8 & 7 & 36 \\
\hline 19 & 9 & 8 & 37 \\
\hline 20 & 10 & 10 & 35 \\
\hline Mean & 8.9 & 8.8 & $35 \cdot 4$ \\
\hline SD & $1 \cdot 5$ & 1.6 & $2 \cdot 3$ \\
\hline
\end{tabular}

TABLE 2

SUMMARY OF VALUES OF INTRAVENTRICULAR PRESSURE (MMHG) AT DIFFERENT MOMENTS

\begin{tabular}{lccc}
\hline \multirow{2}{*}{$\begin{array}{l}\text { Case } \\
\text { no. }\end{array}$} & $\begin{array}{c}\text { Initial } \\
\text { intraventricular } \\
\text { pressure }\end{array}$ & Intraventricular pressure increase \\
\cline { 3 - 4 } & & Blood pressure & $\begin{array}{c}\text { Respiration } \\
\text { changes }\end{array}$ \\
\hline$!^{*}$ & 6 & 70 & 109 \\
$2^{*}$ & 10 & 95 & 118 \\
3 & 10 & 96 & 117 \\
$4^{*}$ & 9 & 95 & 124 \\
$5^{*}$ & 7 & 96 & 110 \\
$6^{*}$ & 10 & 88 & 112 \\
$7^{*}$ & 10 & 91 & 110 \\
8 & 8 & 95 & 117 \\
9 & 10 & 93 & 115 \\
$10^{*}$ & 11 & 97 & 112 \\
$11^{*}$ & 7 & 93 & 111 \\
$12^{*}$ & 11 & 93 & 110 \\
$13^{*}$ & 7 & 92 & 115 \\
$14^{*}$ & 10 & 96 & 112 \\
$15^{*}$ & 7 & 90 & 113 \\
$16^{*}$ & 10 & 91 & 110 \\
17 & 8 & 93 & 113 \\
$18^{*}$ & 8 & 93 & 118 \\
19 & 9 & 88 & $114( \pm 3 \cdot 8)$ \\
$20^{*}$ & 10 & 95 & \\
\hline Mean (SD) & $9( \pm 1 \cdot 5)$ & $92( \pm 5 \cdot 7)$ & \\
\hline & & & \\
\hline
\end{tabular}

* In these animals a clear periodic respiration was observed. was $35 \cdot 4 \pm 2 \cdot 3 \mathrm{mmHg}$ (Table 1). At that moment, no rise of arterial pressure was seen, nor a change in respiratory pattern. Only when the ventricular pressure had reached a mean value of $92 \cdot 0 \pm 5 \cdot 8$ $\mathrm{mmHg}$ did arterial pressure rise, and respiration changes did not occur until 113.6 $\pm 3.8 \mathrm{mmHg}$ (Table 2). At this time in 15 of 20 cats periodic respiration (Fig. 2) was observed which changed to rapid respiration similar to central neurogenic hyperventilation when the ventricular pressure was $113 \cdot 1 \pm 4 \cdot 1 \mathrm{mmHg}$ (Fig. 3). All animals showed a tachypnoea.

\section{DISCUSSION}

On the basis of our findings we would suggest that the process of transtentorial herniation has two phases, occurring when a pressure gradient of a certain value has developed between the supra- and infratentorial compartment-namely, (1) the anatomical phase, in which communication between supra- and infratentorial phase via the tentorial hiatus has been interrupted by displacement of cerebral tissue; (2) the clinical phase, in which a vegetative change occursnamely, an increase of arterial pressure and a change in respiratory pattern.

The fact that the anatomical phase of transtentorial herniation is not at first accompanied by the appearance of clinical-vegetative signs speaks for Scheinker's (1945) conception that herniation of the gyrus hippocampus on its own is not sufficient to cause neurovegetative changes.

The first perceived change in the clinical phase of the incarceration appeared at mean pressure of $92.0 \pm 5.8 \mathrm{mmHg}$ in the supratentorial area and $35.4 \pm 2 \cdot 3 \mathrm{mmHg}$ in the infratentorial area and consisted of a rise of arterial blood pressure. This increase of blood pressure is necessary to maintain cerebral circulation when the cerebral arterioles are already maximally open.

I am grateful to $\mathrm{Mr} \mathrm{H}$. Flanderijn and $\mathrm{Mr} \mathrm{Th}$. Geerlings of the Department of Experimental Neurosurgery for their technical help, to Miss A. Hartlief who prepared the manuscript, and to Miss T. Schut for her statistical help.

\section{REFERENCES}

Beks, J. W. F., Weeme, C. A. ter, Ebels, E. J., Walter, W. G., and Wassenaar, J. S. (1965). Increase in intraventricular pressure in cold induced cerebral oedema. Acta Physiologica et Pharmacologica Neerlandica, 13, 317-329. 
Langfitt, T. W., Weinstein, J. D., Kassell, N. F., and Simeone, F. A. (1964). Transmission of increased intracranial pressure. I. Journal of Neurosurgery, 21, 989-997.

Naunyn, B., and Schreiber, J. (1881). Über Gehirndruck. Archiv für experimentelle Pathologie und Pharmakologie, 14, 1-112.

Pia, H. W. (1957). Die Schädigung des Hirnstammes bei den raumfordernden Prozessen des Gehirns. Acta Neurochirurgica (Wien) Suppl. 4.

Scheinker, I. M. (1945). Transtentorial herniation of the brain stem. Archives of Neurology and Psychiatry (Chic.), 53, 289-298.

Seeger, W. (1968). Atemstörungen bei intrakraniellen Massenverschiebungen. Acta Neurochirurgica (Wien) Suppl. 17. 